\title{
https://doi.org/10.5585/exactaep.v19n1.11153
}

Check for updates

\section{A EVOLUÇÃO DOS NÚCLEOS DE INOVAÇÃO TECNOLÓGICA NO BRASIL NO PERÍODO DE 2006 A 2016}

\author{
THE EVOLUTION OF THE TECHNOLOGICAL INNOVATION CENTER IN BRAZIL IN \\ THE PERIOD FROM 2006 TO 2016
}

(iD)

Jecicleide Luckwü Marques ${ }^{1}$

André Marques Cavalcanti ${ }^{2}$

Auristela Maria da Silva ${ }^{3}$

${ }^{1}$ Mestre - Universidade Federal de Pernambuco - UFPE Recife, PE - Brasil

jecicleidel@gmail.com

${ }^{2}$ Doutor - Universidade Federal de Pernambuco - UFPE Recife, PE - Brasil.

andremarques2008@gmail.com

${ }^{3}$ Mestre - Universidade Federal de Pernambuco - UFPE Recife, PE - Brasil

auristela.msilva@gmail.com

Recebido em: 12 dez. 2018

Aprovado em: 08 maio 2019

Cite como - American Psychological Association (APA)

Marques, J. L., Cavalcanti, A. M., \& Silva, A. M, da. A. (2021, jan./mar.). A evolução dos núcleos de inovação tecnológica no Brasil no período de 2006 a 2016. Exacta, 19(1), 210224. https://doi.org/10.5585/exactaep.v19n1.11153.
Resumo: A Inovação, por meio da disseminação do conhecimento e da transferência de tecnologia, destaca-se como elemento importante para o desenvolvimento de uma nação e de sua economia. A universidade tem um importante papel na formação de recursos humanos altamente qualificados para o trabalho com desenvolvimento tecnológico e inovação, cooperando para a formação de profissionais e para a melhoria da competitividade empresarial no desenvolvimento econômico da nação. A presente pesquisa discorre sobre a importância da relação Universidade-Empresa para a transferência de tecnologias, propondo analisar a evolução e atuação dos Núcleos de Inovação Tecnológica no período de 2006 a 2016 no Brasil, institucionalizados nas Universidades Federais e a sua importância para a transferência tecnológica no Brasil. Na pesquisa constatou-se o avanço no número de núcleos implantados, em sua capacidade de difusão e proteção da Propriedade Intelectual, mas pouca capacidade de interação Universidade-Empresa refletindo na baixa transferência das tecnologia para a sociedade.

Palavras chave: Inovação. Transferência de Tecnologia. Universidade.

Abstract: Innovation, through the dissemination of knowledge and transfer of technology, stands out as an important element for the development of a nation and your economy. The University has an important role in the formation of highly qualified human resources to work with technological development and innovation, cooperating for the training of professionals and to improve business competitiveness in the economic development of the nation. This research discusses the importance of University-company relationship to technology transfer and propose to analyze the evolution and performance of the cores of technological innovation in the period from 2006 to 2016 in Brazil, institutionalized in Federal universities and your importance to technology transfer in Brazil. In the survey it was found the breakthrough in the number of institutions in your deployed broadcast capacity and protection of intellectual property, but little capacity of universityenterprise interaction reflecting downtown transfer of technology to society.

Key words: Innovation. Technology transfer. University. 


\section{Introdução}

Observa-se um consenso, entre autores, sobre a importância da inovação, para o desenvolvimento de uma nação e de sua economia. Enquanto alguns países procuram melhorar as suas bases tecnológicas para buscar a competitividade, outros necessitam continuar desenvolvendo tecnologia para não perder o espaço que alcançaram, e consequentemente se destacando como nação inovadora (Lotufo, 2009; Pires \& Quintella, 2015).

Com a intenção de avançar em busca do desenvolvimento tecnológico e econômico por meio da inovação, o Brasil tem realizado ações de fortalecimento das políticas públicas para inovação, valorização da cultura de proteção da propriedade intelectual, da transferência de tecnologia e com maior interação com os atores do Ecossistema de Inovação tem caminhado para minimizar as dificuldades culturais e sociais de interação da academia e as empresas.

Para o desenvolvimento da Inovação, é necessário que os atores do Ecossistema de Inovação, governo, empresa, universidade e sociedade, atuem de maneira eficiente. Caberá ao governo a criação de um sistema legal para apoiar e desenvolver as mudanças sistemáticas, o fomento as iniciativas de avanço tecnológico da industrial e o apoio a formação de mão de obra qualificada para a pesquisa e para a melhoria da capacidade inovadora nas empresas. As empresas, no Brasil, ainda investem pouco em inovação, pois o risco neste tipo de investimento é alto. Entanto, o uso e conhecimento das novas leis de apoio às iniciativas inovadoras têm melhorado a participação das empresas nos avanços tecnológicos e na busca por parcerias com as empresas para minimizar os riscos do investimento.

Autores como Santos (2009) Kim e Nelson (2005) concordam que a universidade é ator importante para o avanço da tecnologia, seja por meio da formação dos profissionais com capacidade de desenvolver pesquisa no espaço produtivo, seja por meio da oferta de tecnologias já desenvolvidas em seus espaços ou mesmo do conhecimento acadêmico aplicado na indústria por meio da transferência de conhecimento. Em todas as situações citadas anteriormente, as universidades possuem capacidade de cooperação para o desenvolvimento de novas tecnologias.

Segundo Lundvall e Johnson (2005), a proximidade entre empresas, os institutos de pesquisa e a mão de obra qualificada potencializam a criação de ambientes inovadores, pois impulsiona a proximidade entre esses atores e o conhecimento. Porém, Santos (2011) alerta para um cuidado no caso do Brasil, pois apenas a reunião desses elementos pode não ser suficiente, se não se levar em consideração a realidade local, a estrutura social e econômico, bem como o ambiente institucional onde a cultura empresarial ainda não está voltada à inovação.

O papel principal dos Núcleos de Inovação Tecnológica (NITs) é ser um agente de proteção do conhecimento e de transferência de tecnologia nas universidades e institutos de pesquisa. Para cumprir o este papel, é necessário uma estrutura física e gerencial que facilite as relações internas de prospecção 
de tecnologias geradas nos espaços de pesquisa e parcerias que possibilitem adoção e absorção das tecnologias geradas para as indústrias.

Neste sentido, o presente artigo nos apresenta como os Núcleos de Inovação Tecnológica evoluíram no período de 2006 a 2016, onde temos como ponto inicial a implementação da Lei da Inovação (№ 10.973/2004) pelas Universidades e ponto final da análise a criação do novo Marco Legal da Inovação (Lei n. 13.243, 2016). Realizamos uma análise comparativa da evolução das competências e desenvolvimento dos NITs utilizando os dados contidos no Relatório FORMICT por conter as informações coletadas pelas Instituições de Ciência e Tecnologia (ICTs) públicas do Brasil no tocante a criação, implementação e desenvolvimento das competências dos NITs.

O presente artigo está estruturado inicialmente com esta introdução, no tema Propriedade Intelectual, Transferência de Tecnologia para Inovação e os Núcleos de Inovação Tecnológica, na terceira parte apresentamos a metodologia, na quinta parte a análise dos dados e finalizando com a conclusão.

\section{Referencial Teórico}

Neste capítulo abordaremos os temas sobre propriedade intelectual, transferência de tecnologia e os Núcleos de Inovação Tecnológica.

\subsection{Propriedade Intelectual}

Segundo a Declaração Universal dos Direitos Humanos, determinada na Assembleia Geral da Organização das Nações Unidas [ONU] (1948), a proteção dos interesses morais e materiais que the correspondam em razão de autoria sobre produção científica, literária ou artística é um direto. No Brasil a Constituição Federal garante este direito em seu capitulo 50 §29, assegurando privilégio temporário para utilização de inventos industriais, propriedade de marcas, nomes de empresas e outros signos distintivos visando o interesse, social e o desenvolvimento tecnológico e econômico do país (Constituição do Brasil, 1988).

A importância da proteção eficiente à propriedade intelectual coopera tanto para o desenvolvimento econômico, como para mudanças técnicas, difusão do conhecimento, expansão de recursos humanos e desenvolvimento industrial de um país (Haase, Araújo, \& Dias, 2005; Sherwood, 1992).

No Brasil o órgão responsável pela proteção dos Diretos à Propriedade Industrial é o Instituto Nacional de Propriedade Industrial (INPI). O INPI é o responsável por expedir a carta patente ou o registro da marca que tem como objetivo assegurar ao titular o direto de impedir terceiros de praticar atos ilícitos contra a invenção patenteada ou registrada. 
Embora exista um aporte legal para apoiar a proteção da Propriedade Intelectual, a cultura de proteção é pouco conhecida e utilizada no Brasil, e os dados do INPI indicam que o país pouco protege as suas invenções. No Gráfico 1, observa-se que os pedidos de patente dos inventores não residentes no Brasil são superiores aos pedidos dos residentes ao longo de 10 anos analisados. Observa-se que a evolução da cultura de proteção ao longo dos 10 anos obteve uma evolução gradativa entre os residentes, mas sem crescimento significativo.

Gráfico 1 - Pedido de Patente de Invenção por origem do depositante, 2007-2016

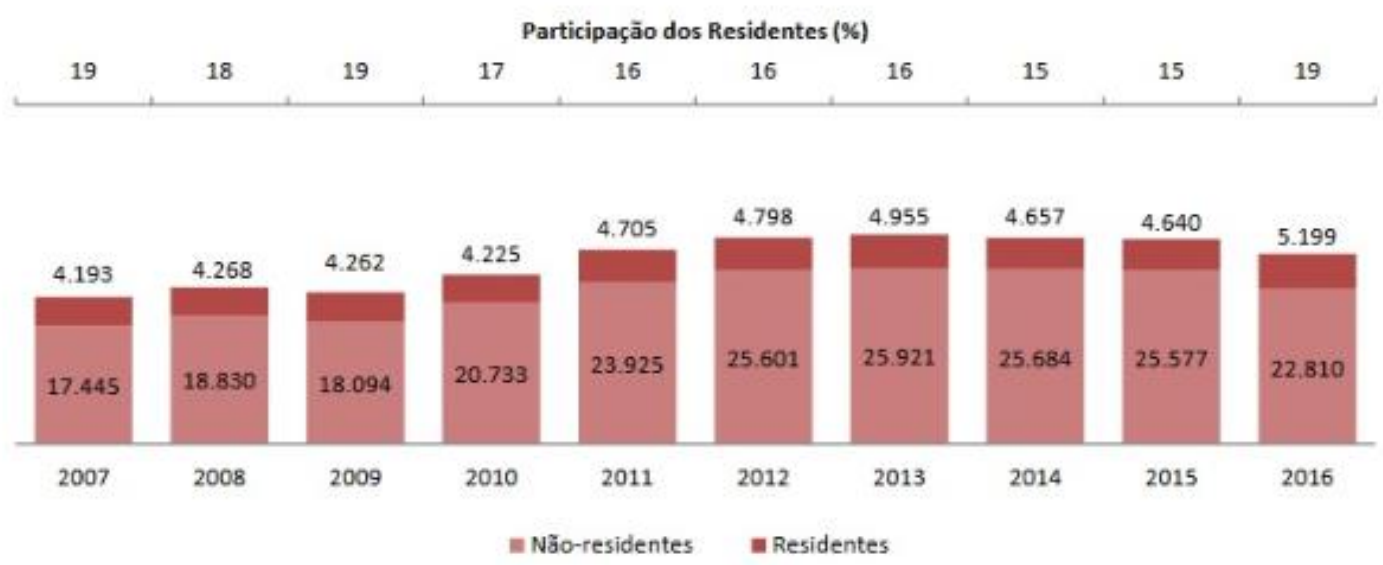

Fonte: INPI, Assessoria de Assuntos Econômicos, BADEPI (2017).

Segundo dados do Instituto Nacional de Propriedade Industriais [INPI] (2017), entre os dez primeiros depositantes de patentes em 2016, nove são oriundos de universidades. Embora as universidades estejam entre os principais depositantes de patente de residentes, a cultura de proteção por meio de Propriedade Intelectual caminha numa velocidade inferior a velocidade que caminha a geração do conhecimento publicado das Universidades. A publicação de artigos brasileiros ocupa um lugar de destaque na participação de conhecimento científico, que é medido pelo número de artigos internacionais indexados com produção anual.

\subsection{Transferência de Tecnologia para Inovação}

Dubickis and Gaile-Sarkane (2013, p. 968) analisaram o conceito de inovação, transferência de tecnologia (TT) e suas características, identificando diferentes perspectivas. Para alguns participantes da pesquisa, a transferência de tecnologia inclui a inovação; para outros a inovação inclui a transferência 
de tecnologia; e por fim que inovação e transferência de tecnologia se sobrepõem, unindo-se um ao outro conceito.

Arena e González (2018) realizaram um estudo bibliográfico sobre os modelos de transferência de tecnologia, bem como os elementos que colaboram para a interação da universidade-indústria. Os autores consideraram o modelo conceitual de TT de colaboração universidade-indústria, como um processo linear, onde há um agente que transmite a mensagem para outro que é o receptor, além de mecanismos e relações facilitados pela interação realizada pelo Escritório de Transferência de Tecnologia. Esses autores consideram que há mecanismos e meios para a TT. Os meios podem ser uma patente, um protótipo, um artigo ou conhecimento científico e técnico. E os mecanismos são a maneira que a apresentação do objeto será transferida, podendo ocorrer como licença, know-how, etc.

Segundo Santos, Solleiro e Lahorgue (2004), as tecnologias diferem entre si, seja pelo estágio em que se encontram ou pela área de aplicação, sendo que cada uma tem a sua especificidade. Para Dias e Porto (2014), as tecnologias diferem inclusive pela capacidade de serem ou não desenvolvidas em uma indústria, pois o inventor nem sempre está pensando na possibilidade de produção em massa. Neste sentido, os autores alertam que para ocorrer a transferência de tecnologia, além de uma tecnologia a transferir, deve haver uma disposição por parte do detentor da tecnologia, uma adoção da tecnologia licenciada pelo licenciador, e acima de tudo, que esta tecnologia seja algo inovador, para que possa diminuir os riscos do negócio.

\subsection{Os Núcleos de Inovação Tecnológica}

Os Núcleos de Inovação Tecnológica (NITs) foram criados com o objetivo de desenvolverem um diálogo entre as Instituições de Ciência e Tecnologia e as empresas, assumindo a partir de sua criação várias competências, entre elas proteger as tecnologias desenvolvidas em seus laboratórios e centros de pesquisa, disseminar a cultura de proteção, desenvolver pesquisas conjuntas e viabilizarem a transferência das tecnologias.

No século XX, com o desenvolvimento industrial e a abertura do mercado estrangeiro, além da pressão econômica gerado pela competitividade mundial e a globalização, o Brasil reaparece em um cenário de busca pelo desenvolvimento econômico e tecnológico. No novo século era preciso adequar a legislação para o novo cenário de desenvolvimento tecnológico e competitividade em conhecimento.

Segundo Miranda, Sidulovicz e Machado (2016), com a Lei de Inovação № 10.973/2004 as universidades brasileiras passaram a ocupar um papel de destaque que tem como principais objetivos a Propriedade Intelectual e a Inovação. Foi neste momento que as universidades sentiram a necessidade de criar ou estruturar os seus Núcleos de Inovação Tecnológica. Embora por força de Lei precisassem criar espaços voltados para a inovação, as universidades já percebiam a dificuldade de exercer o seu 
papel de proteção e ampliação da cultura de inovação sem o apoio de uma legislação pertinente, uma estrutura física contingente com o seu papel e de pessoal adequada, além de uma cultura de proteção do conhecimento para apoiar a cultura de proteção institucionalizada na academia (Miranda, Sidulovicz, \& Machado, 2016).

Durante os 11 anos, entre a implementação da Lei da inovação № 10.973/2004 e a sua alteração em através do Marco Legal da Lei № 13.243/2016, melhorias são notórias no que tange a algumas das competências delegadas aos NITs. A disseminação da cultura de Propriedade Intelectual alcançaram saltos relevantes, embora ainda de maneira insatisfatória quando a análise é feita entre os depositantes residentes e não residentes (INPI, 2017). O desenvolvimento tecnológico, embora tenha obtido um avanço nas regiões sul e sudeste do país, não avançaram na mesma proporção nas regiões norte e nordeste do país (Casali, Silva, \& Carvalho, 2010, p.548).

Para algumas Instituições de Ciência e Tecnologia (ICTs) a Lei de Inovação veio colaborar com o empenho de pesquisadores que já estavam comprometidos com a inovação em espaços já existentes que eram chamados de Agencias de Inovação, Centros de Pesquisa e Desenvolvimento ou Escritórios de Transferência de Tecnologias, mas sem amparo legal. Em outras ICTs, a lei foi o marco inicial para o surgimento destes espaços (Torkomian, 2009).

Seja por força da Lei № 10.973/2004 ou por vontade própria, foi com a promulgação desta legislação que se iniciaram os debates nas universidades sobre a importância e o papel deste espaço como responsável pela inovação e transferência de tecnologias nas universidades. Algumas ICTs se viram na urgência de criar estes espaços físicos, outras melhorando as condições estruturais ou de pessoal ao mesmo tempo em que necessitavam cumprir exigências legais e executar as "competências mínimas" exigidas para um NIT.

Embora recebida pelos atores do Sistema de Inovação com entusiasmo, a Lei de Inovação foi implantada no meio de crítica que ela tinha um enfoque na proteção e ainda estava muito engessada para as ações de transferência de tecnologias, autonomia dos NITs e definição de recursos para a sua organização.

A interação Universidade-Empresa nos NITs só é possível por meio de uma gestão estratégica bem consolidada na execução de suas competências. Para isso é necessário definir um modelo de gestão para o NIT. Segundo (Toledo, 2009), há dois modelos de estrutura, que pode aumentar a interação e resultar em Transferência da Tecnologia: Modelo do Berço ao Túmulo e o Modelo de Compra e Venda.

No Modelo do Berço ao Túmulo o papel principal é do gerente de projetos que acompanha a tecnologia em todo o seu desenvolvimento do nascimento até a transferência. O gerente toma decisão sobre a tecnologia do comunicado de invenção até a assinatura do contrato, e possui um perfil empreendedor com experiência industrial e com base na academia. 
O modelo de Compra e Venda possui as seguintes características: a tecnologia é o foco principal, portanto há responsabilidades dividida para cada papel a desempenhar. Neste modelo há necessidade de um profissional que se preocupa com a proteção, responsabilizando-se pela patenteabilidade e com um perfil profissional mais técnico; e outro profissional que se preocupa com a comercialização, com um perfil empreendedor, dinâmico e articulador.

Toledo (2009) apresenta a sugestão que ao estruturar os NITs, ambos os modelos sejam considerados e avaliados, mas que na maioria dos escritórios internacionais ainda predomina o primeiro modelo. No Brasil, observa-se a adoção do modelo Compra e Venda uma vez que, em sua maioria, são docentes da universidade que assumem a gestão dos NITs, juntamente com as competências de ensino e pesquisa para o qual foram contratados.

Neste sentido, a articulação do NIT ocorre para difusão tecnológica visando identificar as melhores pesquisas que representam a possibilidade de aproveitamento na indústria, acompanha o desenvolvimento em que o pesquisador deve pensar que o produto deverá ser desenvolvido em escala industrial e o licenciamento da tecnologia. Este procedimento só é possível quando o Sistema Nacional de Inovação está funcionando de maneira articulada e o NIT possui competência técnica para realizar as tarefas que lhe são inerentes.

\section{Metodologia}

Na presente pesquisa foram utilizados o levantamento bibliográfico, a pesquisa documental e uma abordagem quantitativa.

Segundo Gil (1999), a pesquisa bibliográfica e a pesquisa documental podem ser confundidas. O autor destaca que a principal diferença entre ambas é a natureza das fontes pesquisadas. A pesquisa bibliográfica é desenvolvida mediante material já publicado, baseando-se em citações de livros e artigos científicos. Esses materiais reúnem conhecimento sobre a temática pesquisada. Já a pesquisa documental é baseada em documentos que não receberam um tratamento analítico ou que podem ser reelaborados dependendo dos objetivos da pesquisa.

De acordo com a natureza, esta pesquisa é quantitativa, uma vez que utiliza dados do Relatório FORMICT dos anos base 2006 a 2016. Seguindo ensinamentos de Richardson (1989), este método caracteriza-se pelo emprego da quantificação, tanto nas modalidades de coleta de informações, quanto no tratamento dessas através de técnicas estatísticas, desde as mais simples até as mais complexas.

O relatório do FORMICT é elaborado pelo Ministério da Ciência, Tecnologia, Inovação e Comunicação (MCTIC) e tem o propósito de apresentar e acompanhar a Política de Propriedade Intelectual das Instituições Cientificas, Tecnológicas e de Inovação do Brasil. 
O formulário apresenta as informações coletadas pelas ICTs públicas e privadas do Brasil. Vale salientar que as ICTs públicas são obrigadas a responder o formulário e as ICTs privadas respondem voluntariamente. A partir do Novo Marco Legal, as ICTs privadas que receberem recurso públicos também serão obrigadas a responder.

\section{Análise dos dados}

Com a institucionalização da Lei da Inovação (Lei n. 10.973, 2004) os NITs foram gradativamente sendo criados nas instituições públicas.

Para acompanhar os dados fornecidos pelas Instituições Científicas e Tecnológicas (ICTs) ao MCTI, foi criado um formulário para tratar as informações sobre a Política de Propriedade Intelectual das Instituições Científicas e Tecnológicas do Brasil, denominado FORMICT.

Para fins da Lei de Inovação, são consideradas ICTs os órgãos ou entidades da administração pública que tenham por missão institucional, dentre outras, executar atividades de pesquisa básica ou aplicada de caráter científico ou tecnológico. Embora não exista obrigatoriedade na Lei de Inovação para que instituições privadas apresentem informações, o cadastro voluntário por essas instituições integra a base de dados do MCTI e faz parte deste relatório.

O Gráfico 2 apresenta um perfil das instituições participantes do relatório FORMICT ao longo de 11 anos. Observa-se que em 2006 houve a participação de 43 instituições, e em 2016 esse número foi de 278 instituições. As regiões com menor número de respondentes foram o Norte e o Centro-Oeste, com um total de 25 e 26 instituições, respectivamente. Na consolidação dos dados do relatório FORMICT referente ao estágio de implementação dos NITs, classificados como implementado, em implementação ou não implementado, observa-se uma gradativa elevação de todos os estágios de implementação e do número de instituições participantes. 
Gráfico 2 - Instituições participantes do Relatório FORMICT no período de 2006 - 2016

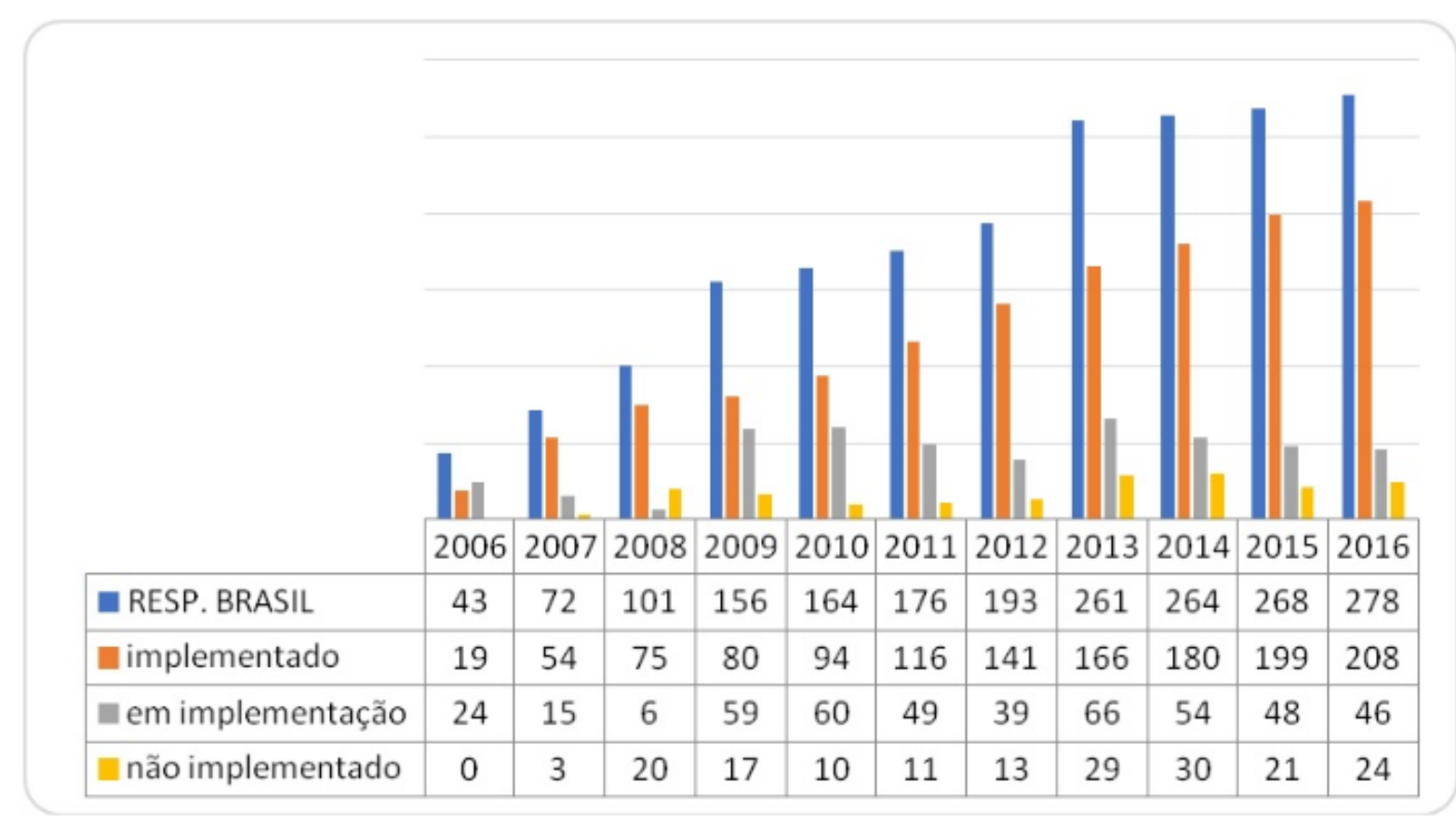

Fonte: Autores com base no Relatório FORMICT - MCTIC de 2006 - 2016.

Quanto a Implementação da Política de Inovação, o Gráfico 3 mostra o resultado no período de 2009 a 2016, pois os dados dos anos anteriores ainda não estavam disponíveis. Observa-se uma prática comum na criação do NITs no Brasil que ocorreu inicialmente, com a montagem da estrutura física e, só posteriormente, pela estrutura legal e organizacional. Cita-se o exemplo do NIT/UFPE que foi implantado em 2002 e a política de inovação é de 2004.

Gráfico 3 - Comparativo NITs Implantados e a implementação da Política de Inovação

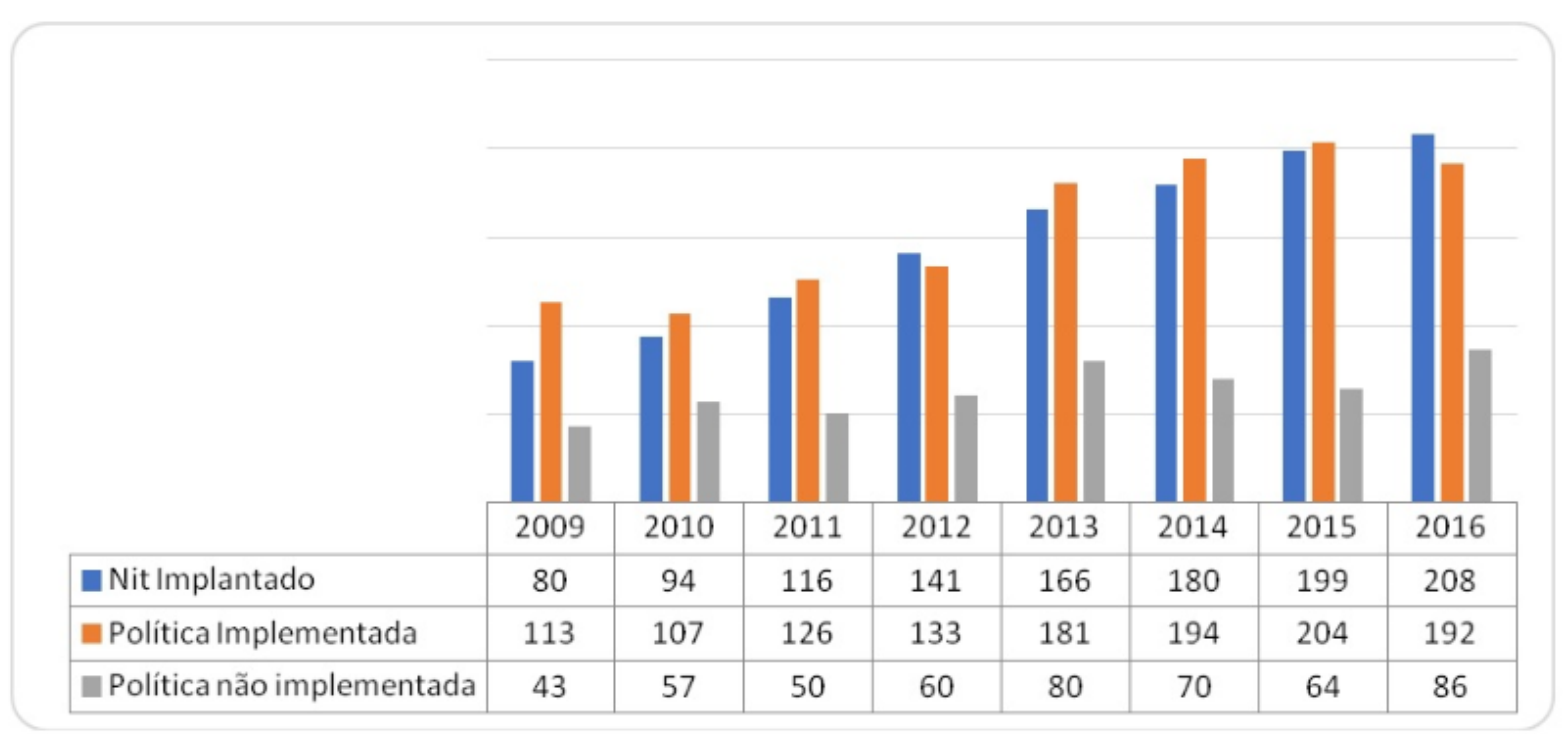

Fonte: Autores com base no Relatório FORMICT - MCTIC de 2006 - 2016. 
No Gráfico 4, temos um comparativo dos pedidos de patente requeridos e concedidos. Observase que a linha de pedidos concedidos não acompanha o crescimento dos pedidos requeridos, sendo este fato justificado pelo backlog do INPI. Ainda no Gráfico 4, observa-se o número de pedidos de patente em 2009, com 583 patentes concedidas. Este comportamento é superado apenas pelo ano de 2016, com 813 patentes concedidas.

Gráfico 4 - Evolução dos depósitos de pedidos de patentes requeridos e concedidos pelas universidades públicas

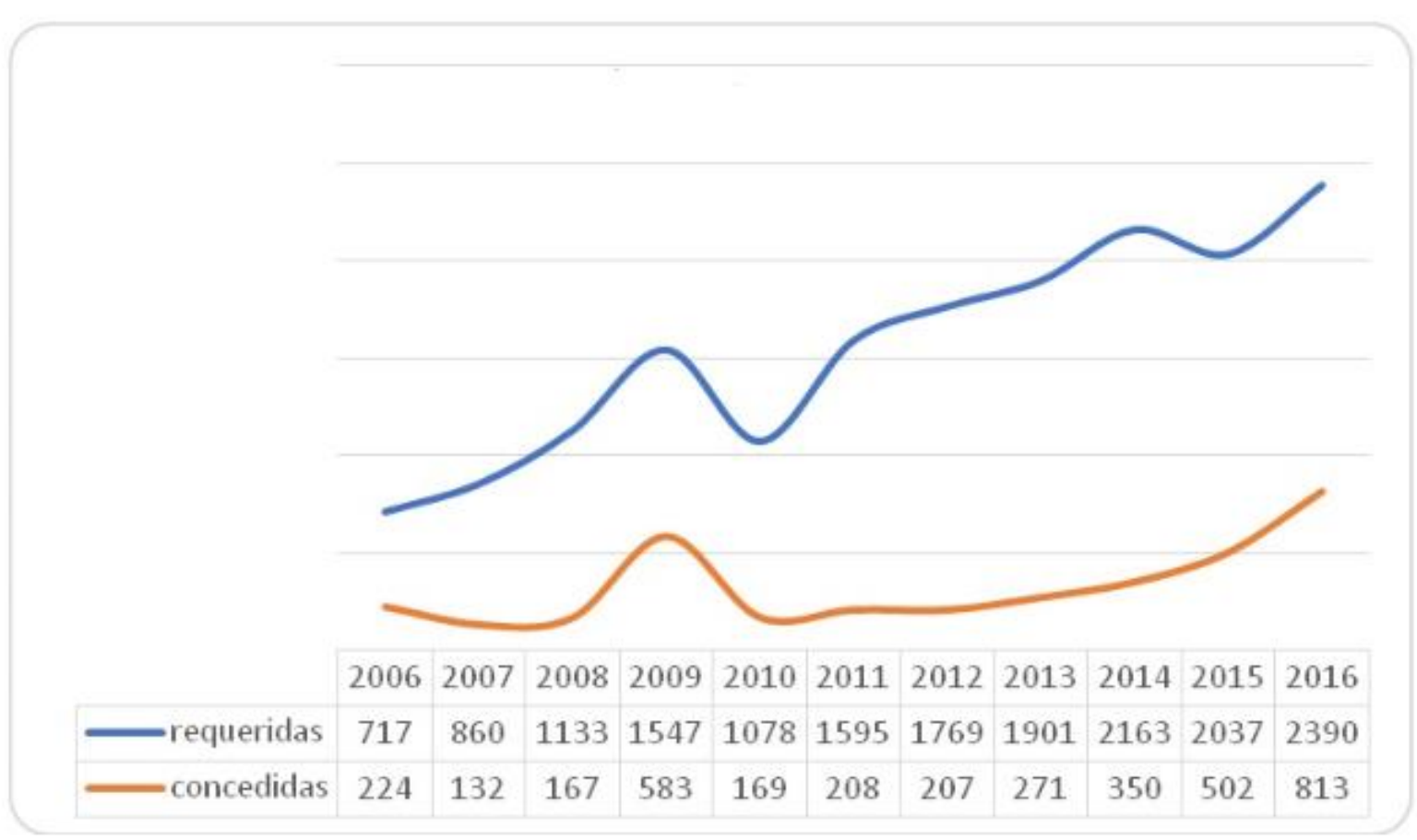

Fonte: Autores com base no Relatório FORMICT - MCTIC de 2006 - 2016.

Segundo o INPI (2017), os 09 maiores depositantes de pedidos de patente foram as universidades, embora depositantes residentes ainda não superaram os depositantes não residentes, o que indica o aproveitamento do mercado interno para a negociação de tecnologias.

Segundo pesquisa realizada por Torkomian (2009), 90\% dos NITs entrevistados se dedicam as atividades referente à Propriedade Intelectual. Para autora, as instituições dividem as suas ações tanto para a proteção, como à disseminação da Propriedade Intelectual e Transferência de Tecnologia, por meio de seminários, capacitações, palestras e isso tem como resultado a sensibilização da comunidade que satisfeito, torna-se também um divulgador das ações do NIT.

Ainda como resultado da pesquisa, Torkomian (2009) detalha as principais atividades desenvolvidas pelos NITs nos anos 2013 a 2016. Segundo a pesquisadora, as atividades dos NITs consideradas essenciais oscilaram entre $48,9 \%$ e $76,1 \%$, sendo elas focadas em proteção à propriedade 
intelectual, tais como: decidir pela conveniência e promover a proteção das criações desenvolvidas na instituição, acompanhar o processamento dos pedidos e a manutenção dos títulos de PI e zelar pela manutenção da política institucional de estimulo à proteção. Em relação as atividades focadas em transferência de tecnologia e interação, tais como: acompanhar as atividades de pesquisa, apoiar o empreendedorismo, negociar projetos, comercializar tecnologia, negociar ativos de PI, entre outras, a pesquisadora encontra um intervalo entre $14 \%$ e $42 \%$.

Quanto à Transferência de Tecnologia e o Montante Resultante dos Contratos, no Gráfico 5 observa-se os menores resultados no período de 2006 a 2008. É importante ressaltar, que neste período, os NITs estavam em estruturação.

Ainda no Gráfico 5, observa-se que no ano de 2006, ano de menor desempenho, os valores relativos a royalties de terceiros com exclusividade foram de $\mathrm{R} \$ 593$ mil (73\%); sem exclusividade foram de $\mathrm{R} \$ 100$ mil (12\%) e outras formas de transferência somaram $\mathrm{R} \$ 115$ mil (15\%). Observa-se que este valor após a consolidação dos NIT foi elevando-se ao longo dos anos, podendo indicar a eficiência das ICT na transferência de tecnologia no que tange a negociação.

Gráfico 5 - Montantes dos Contratos de Tecnologias resultantes de Transferência de Tecnologia

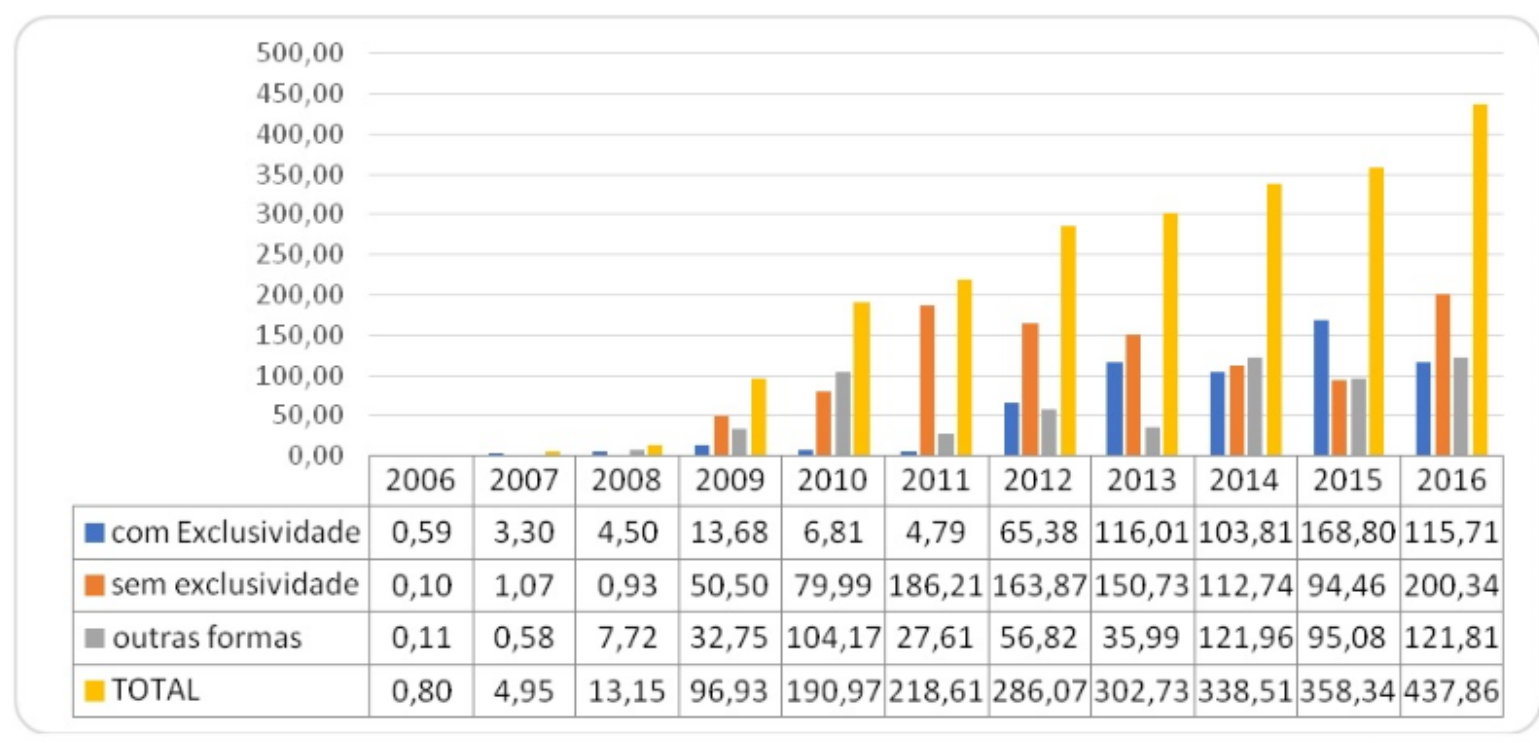

Fonte: Autores com base no Relatório FORMICT - MCTIC de 2006 - 2016.

Ainda no Gráfico 5, mostra-se um movimento dos NITs para a transferência de tecnologia a partir de 2009. Para os contratos sem exclusividade, teve uma elevação significativa em 2011, declinando gradativamente até 2015, e retomando o crescimento em 2016. Observa-se, ainda em 2015 uma elevação no resultado de transferência de tecnologia com exclusividade, obtendo uma retração em 2016. 
Os Estados Unidos possuem a Association of University of Technology Managers (AUTM), que é a agencia responsável pela transferência de tecnologia e anualmente publicam a sua performance com os indicadores mais importantes. Na pesquisa do ano fiscal de 2016 foram convidadas pela AUTM 309 instituições de ciência e tecnologia dos Estados Unidos para participar da pesquisa. Obteve-se a participação de 195 instituições, com uma taxa de retorno de 63,1\%. Os entrevistados são 165 Universidades, 29 hospitais e instituições de pesquisa e uma empresa de investimento em tecnologia de terceiros. O resultado da pesquisa é publicado em resumo gratuito na página da AUTM e o relatório completo possui um custo diferenciados para sócios, não sócios e instituições respondentes (Association of University of Technology Managers [AUTM], 2016).

No Gráfico 6, mostram-se uma comparação entre o Brasil e os Estados Unidos no que tange a proteção e de licenciamento, no entanto é preciso considerar a diferença de investimento em pesquisa e desenvolvimento nos dois países. Também é preciso considerar a maturidade, organização física, recursos humanos e gestão das instituições no Brasil e nos Estados Unidos para compreender esta diferença.

Gráfico 6 - Comparativo dos resultados da AUTM e dos resultados do Brasil

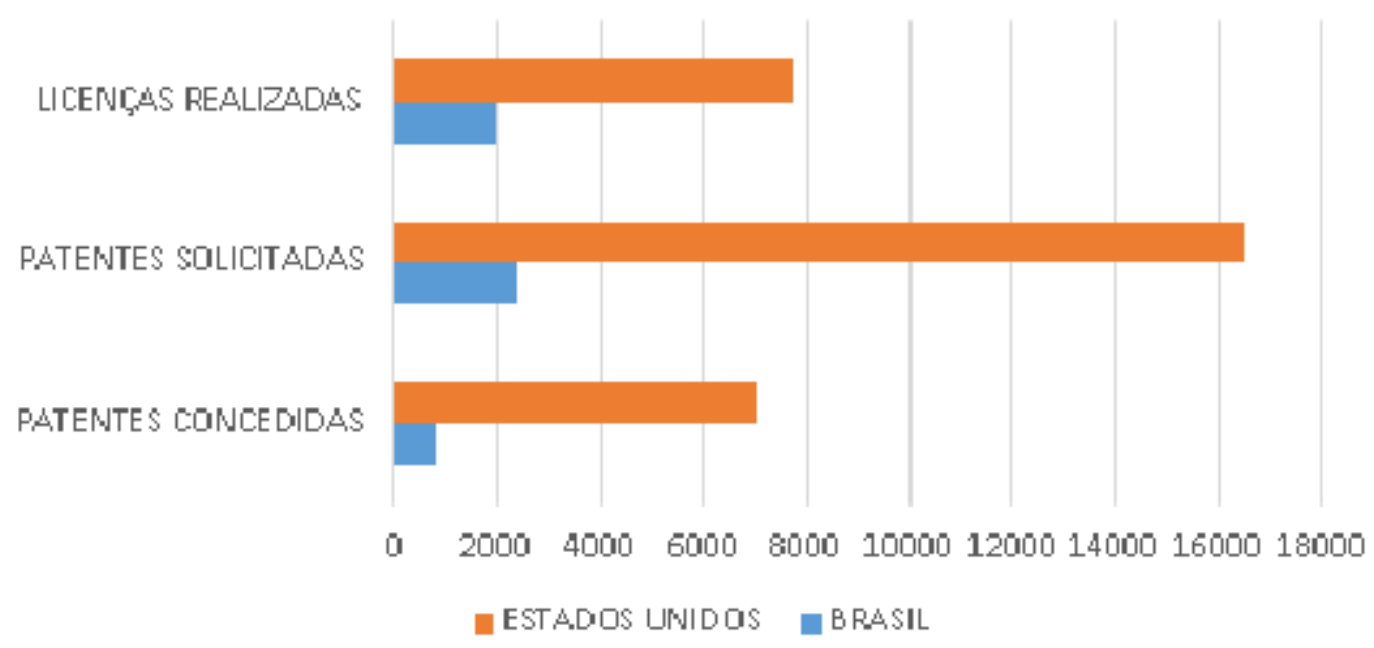

Fonte: Autores com base no Relatório FORMICT - MCTIC de 2006 - 2016

\section{Conclusões}

Este artigo analisou o desenvolvimento dos Núcleos de Inovação Tecnológica ao longo de 11 anos, desde a implementação da Lei da Inovação № 10.973, de 2 de dezembro de 2004. A nossa 
pesquisa teve como foco a evolução das capacidades dos NITs em desenvolver as competências a ele instituídas por lei, e que são de grande importância para a inovação no país.

Constatou-se que houve um aumento no número de NITs implementados nas ICTs do Brasil, no período analisado, em conjunto com implantação de políticas de inovação, que é um instrumento necessário para que o NIT possa cumprir as suas competências.

Apesar do aumento gradativo no cumprimento de suas competências dos NITs no período analisado, observou-se que há resultados mais significativos na proteção da Propriedade Intelectual, em comparação com a Transferência de Tecnologia, o que corrobora com os autores estudados. Nesse sentido, são necessárias ações mais eficazes para que o Brasil avance na Transferência das Tecnologias desenvolvidas nas ICTs.

A transferência de Tecnologia não consegue avançar significativamente ao longo dos anos, e o Brasil permanece na vanguarda da possibilidade de utilizar a inovação para o desenvolvimento do país.

As universidades possuem alto grau de conhecimento o que é comprovado pela elevada produção de artigos científicos publicados anualmente, como resultado de uma cultura de publicação que supera a cultura de proteção.

Como sugestões futuras de pesquisa, pretende-se analisar o retorno financeiro resultante de Transferências de Tecnologia e o custo dos NITs, bem como o impacto das inovações acadêmicas para a sociedade, compreendendo-se assim a importância do conhecimento gerado nestes espaços de pesquisa e conhecimento e o seu retorno social e econômico para o país.

\section{Referências}

Association of University of Technology Managers. (2016). Driving the Innovation Economy academic technology transfer in numbers. Recuperado em 02 de julho, 2018, de https://autm.net/AUTM/media/SurveyReportsPDF/Survey\%20Reports\%20Images/AUTM_2017_Inf ographic_1.pdf

Arenas, J. J., \& González, D. (2018). Technology Transfer Models and Elements in the UniversityIndustry Collaboration. Administrative Science (adm.sci). Recuperado em 04, novembro, 2018, de www.mdpi.com \ournal $\backslash a d m s c i$

Assembleia Geral da ONU. (1948). "Declaração Universal dos Direitos Humanos" (217 [III] A). Paris. Recuperado em 06 maio, 2018, de http://www.ohchr.org/EN/UDHR/Documents/UDHR_Translations/por.pdf

César, J. (2009). Avaliação do Potencial de Potencial de Mercado de Tecnologias Nascentes: A experiência do Programa de Investigação Tecnológica da Unicamp. In: A Gestão Estratégica de Núcleos de Inovação Tecnológica: Cenários, Desafios e Perspectivas. Toledo, P.T.M.(Org.) Campinas: Agencia de Inovação da UNICAMP.

Constituição da República Federativa do Brasil de 1988. (1988). Recuperado em 06 maio, 2018, de http://www.planalto.gov.br/ccivil_03/constituicao/constituicaocompilado.htm 
Lei n. 10.973, de 02 de dezembro de 2004. (2004). Dispõe sobre incentivos à inovação e à pesquisa científica e tecnológica no ambiente produtivo e dá outras providências. Recuperado em 17 dezembro, 2011, de <http://www.planalto.gov.br/ccivil_03/_ato2004-2006/2004/lei/l10.973.htm>

Lei n. 13.243, de 11 de janeiro de 2016. (2016). Dispõe sobre estímulos ao desenvolvimento científico, à pesquisa, à capacitação científica e tecnológica e à inovação. Recuperado em 04 de abril, 2018, em http://www.planalto.gov.br/ccivil_03/_ato2015-2018/2016/lei/l13243.htm

Casali, G. F. R, Silva, O. M., \& Carvalho, F. M. A. (2010). Sistema regional de inovação: estudo das regiões brasileiras, Revista Economia Contemporânea [versão eletrônica],Vol.14, n.3, pp.515-550. ISSN 1415-9848. Recuperado em 10 maio, 2018, de http://dx.doi.org/10.1590/S141598482010000300004

Dias, A. A., \& Porto, G.S. (2014). Como a USP transfere tecnologia?, Organizações \& Sociedades, Vol. 21, n. 70, Salvador, July/Sept. 2014. Recuperado em 24 abril, 2018, de www.scielo.br\scielo.php?script=sci_arttext\&pid

Dubickis, M., \& Gaile-Sarkane, E. (2015). Perspectives on Innovation and Technology Transfer. Anais do 20th International Scientific Conference Economics and Management - (ICEM-2015). Procedia Social and Behavioral Sciences, ${ }^{*}$ pp. 965 - 970. Available online at www.sciencedirect.com

Gil, Antônio Carlos. (1991). Como elaborar projeto de pesquisa. 3. ed. São Paulo: Atlas.

Haase, H, Araújo, E.C, \& Dias, J. (2005). Inovações Visas Pelas Patentes: Exigências Frente às Novas Funções das Univrsidades. Revista Brasileira de Inovação. v.4, n.2, pp.329-362.

Instituto Nacional de Propriedade Industrial .(2017). Indicadores de Propriedade Industrial 2017. (Rio de Janeiro p78). Recuperado em 07 de maio, 2017, de http://www.inpi.gov.br/sobre/estatisticas/arquivos/pagina-inicial/indicadores-de-propriedadeindustrial-2017_versao_portal.pdf

Kim, L., \& Nelson, R. R.(Org.). (2005). Tecnologia, Aprendizado e Inovação: As experiências das Economias de Industrialização Recente. Tradutor: Carlos D. Szlak - Campinas, SP: Editora da Unicamp.

Lotufo, R. A. (2009). A institucionalização de Núcleos de Inovação Tecnológica e a experiência da Inova Unicamp. In: Santos, M. E. R. dos, Toledo, P. T. M. de, \& Lotufo, R. de A. (orgs.). Transferência de Tecnologia: estratégias para estruturação e gestão de Núcleos de Inovação tecnológica. Campinas SP: Komedi).

Lundvall, Bengt-Ake, \& Johnson, Björn. (2005). Promovendo sistemas de inovação como resposta à economia do aprendizado crescentemente globalizada. In: Lastes, H. M. M., Cassiolato, J. E., \& Arroio, A. (Org). Conhecimento, sistemas de inovação e desenvolvimento. Rio de Janeiro, Editora UFRJ/ Contraponto.

Miranda, J.I.R., Sidulovicz, N., \& Machado, D.M. (2016). O desafio da Inovação Tecnológica Dentro da Universidade. (Revista de Desenvolvimento Econômico - RDE - agosto de 2016, Ano XVIII - V2, N.34, Salvador, BA - pp. 389 - 406).

Pires, E.A, \& Quintella, C.M.A.T. Política de Propriedade Intelectual e Transferência de Tecnologia nas Universidades: Uma perspectiva do NIT da Universidade Federal do Recôncavo da Bahia. (2015). Revista Holos, 2015, ano 31, V. 6 pp. 178 - 195. 
Richardson, Roberto Jarry. (1989). Pesquisa social: métodos e técnicas. São Paulo: Atlas.

Santos, M.E.R. (2009). Boas Práticas de Gestão em Núcleos de Inovação Tecnológica. In: A Gestão Estratégica de Núcleos de Inovação Tecnológica: Cenários, Desafios e Perspectivas. Toledo, P.T.M.(Org.) Campinas: Agencia de Inovação da UNICAMP.

Santos, E. C. D. C. (2011). Índice estadual de Ciência, Tecnologia e Inovação como contribuição à melhoria da capacidade de gerência pública. Nova Economia, 21(3), pp. 399-421.

Santos, M. E. R. D., Solleiro, J. L., \& Lahorgue, M. A. (2004). Boas práticas de gestão em escritórios de transferência de tecnologia. Simpósio de Gestão da Inovação Tecnológica, 23, pp. 785-800.

Sherwood, R.M. (1992). Propriedade Intelectual e Desenvolvimento Econômico. São Paulo: EDUSP.

Toledo, P.T.M. (2009). A Gestão Estratégica de Núcleos de Inovação Tecnológica: Cenários, Desafios e Perspectivas. (Agencia de Inovação da UNICAMP).

Torkomian, A.L.V. (2009). Panorama dos Núcleos de Inovação Tecnológica no Brasil. In: A Gestão Estratégica de Núcleos de Inovação Tecnológica: Cenários, Desafios e Perspectivas. Toledo, P.T.M.(Org. Campinas: Agencia de Inovação da UNICAMP. 